\title{
Volar locking plate versus external fixation for unstable distal radius fractures: a systematic review and meta-analysis based on randomized controlled trials
}

Qi Gou ${ }^{1+}$, Xiong Xiong ${ }^{1+}$, Dan Cao ${ }^{2}$, Yuanliang $\mathrm{He}^{1 *}$ and Xu $\mathrm{Li}^{1^{*}}$

\begin{abstract}
Background: The outcomes for volar locking plate (VLP) and external fixation (EF) in distal radius fracture cases remain controversial. The current study of randomized controlled trials (RCTs) aimed to assess VLP and EF, which might benefit distal radius fracture cases.

Methods: RCTs comparing VLP and EF in distal radius fracture cases, until 18 March 2020, were systematically reviewed and summarized. The functional and radiographic outcomes, together with complications, for distal radius fracture cases, were evaluated.

Results: In total, 12 studies comprising 1205 distal radius fracture cases were included. The VLP group had observed lower disability in the arm shoulder and hand score (DASH) at 3rd, 6th, and 12th -month post-operation, with the mean differences (MDs) of $-10.43(95 \% \mathrm{Cl}=-15.77$ to $-5.08, P<0.01),-3.48(95 \% \mathrm{Cl}=-6.37$ to -0.59 , $P=0.02)$, and $-4.13(95 \% \mathrm{Cl}=-6.94$ to $-1.33, P<0.01)$, respectively. The VLP group also had lower visual analog scale scores (VAS) compared to the EF group, with MDs of $-0.10(95 \% \mathrm{Cl}=-0.18$ to $-0.03, P<0.01)$ for the former at 6th -month post-operation. Also, the EF group exhibited better grip strength than that in the VLP group, with MD of $12.48(95 \% \mathrm{Cl}=7.00-17.95, P<0.01)$ at the $3 \mathrm{rd}$ month and $4.54(95 \% \mathrm{Cl}=0.31-8.76, P=0.04)$ at 6 th month. No significant differences in radiographic outcomes were observed between the VLP and EF groups ( $P>$ 0.05). The VLP group had a lower complication rate than that in the EF group.
\end{abstract}

Conclusions: VLP had a lower DASH score and VAS score but with lower grip strength. No significant differences in radiographic outcomes were observed. VLP had a lower complication rate than that of EF.

Keywords: Volar locking plates, External fixation, Putcome, Distal radius fractures, Meta-analysis, RCTs

\footnotetext{
*Correspondence: yuanlianghe88@126.com; lixu1988med@126.com

${ }^{\dagger} \mathrm{Qi}$ Gou and Xiong Xiong contributed equally to this paper.

'Department of Orthopedics, The First People's Hospital of Longquanyi District, 610100 Chengdu, China

Full list of author information is available at the end of the article
}

(c) The Author(s). 2021 Open Access This article is licensed under a Creative Commons Attribution 4.0 International License, which permits use, sharing, adaptation, distribution and reproduction in any medium or format, as long as you give appropriate credit to the original author(s) and the source, provide a link to the Creative Commons licence, and indicate if changes were made. The images or other third party material in this article are included in the article's Creative Commons licence, unless indicated otherwise in a credit line to the material. If material is not included in the article's Creative Commons licence and your intended use is not permitted by statutory regulation or exceeds the permitted use, you will need to obtain permission directly from the copyright holder. To view a copy of this licence, visit http://creativecommons.org/licenses/by/4.0/ The Creative Commons Public Domain Dedication waiver (http://creativecommons.org/publicdomain/zero/1.0/) applies to the data made available in this article, unless otherwise stated in a credit line to the data. 


\section{Background}

Distal radius fracture is very common in the clinic and accounts for about $17 \%$ of all types of fractures [1]. Bridging external fixation (EF), a technique aimed to obtain and maintain fracture alignment, has been widely used for many years. As a traditional and one of the most common treatment methods, EF can achieve acceptable results for distal radius fractures [2]. With about $50 \%$ recurrent displacements and a 20-35\% complication rate $[3,4]$, in recent years, several new technologies have been developed for treating unstable distal radius fractures, one of which is named volar locking plates (VLP) [5].

Since the last decade, VLP are becoming more and more popular for surgical fixation of distal radius fractures [6]. The outcome for distal radius fractures includes malunion and highly unstable fractures [7], and the recent studies that assessed the use of fixed-angle screws within volar plates demonstrated that these can provide satisfactory stability by avoiding joint distraction $[8,9]$.

Several randomized studies were designed to assess the outcome of VLP versus EF for distal radius fracture cases [10, 11]. A meta-analysis [12] aimed to assess EF versus VLP in unstable fractures of distal radial concluded that cases treated with a VLP could obtain better functional outcomes. Another meta-analysis by Zhang et al. [13] reported a drastically opposing conclusion that the two methods had similar functional recovery. However, limited by the smaller sample sizes of the included studies, the two meta-analyses could not report more stratified analyses and could not conclude with more details. Very recently, several randomized controlled trials (RCTs) [14-17] addressing this topic provided new evidence, making it possible to update the results concerning this topic with powerful convincing. Therefore, we systematically conducted the current study to assess and compare the outcomes of VLP versus EF in unstable distal radius fractures.

\section{Methods}

Literature search

Widely used electronic datasets, such as PubMed, MEDLINE, Cochrane Library, and EMBASE databases, were used to search relevant articles until 18 March 2020. The individual and joint keywords of "distal

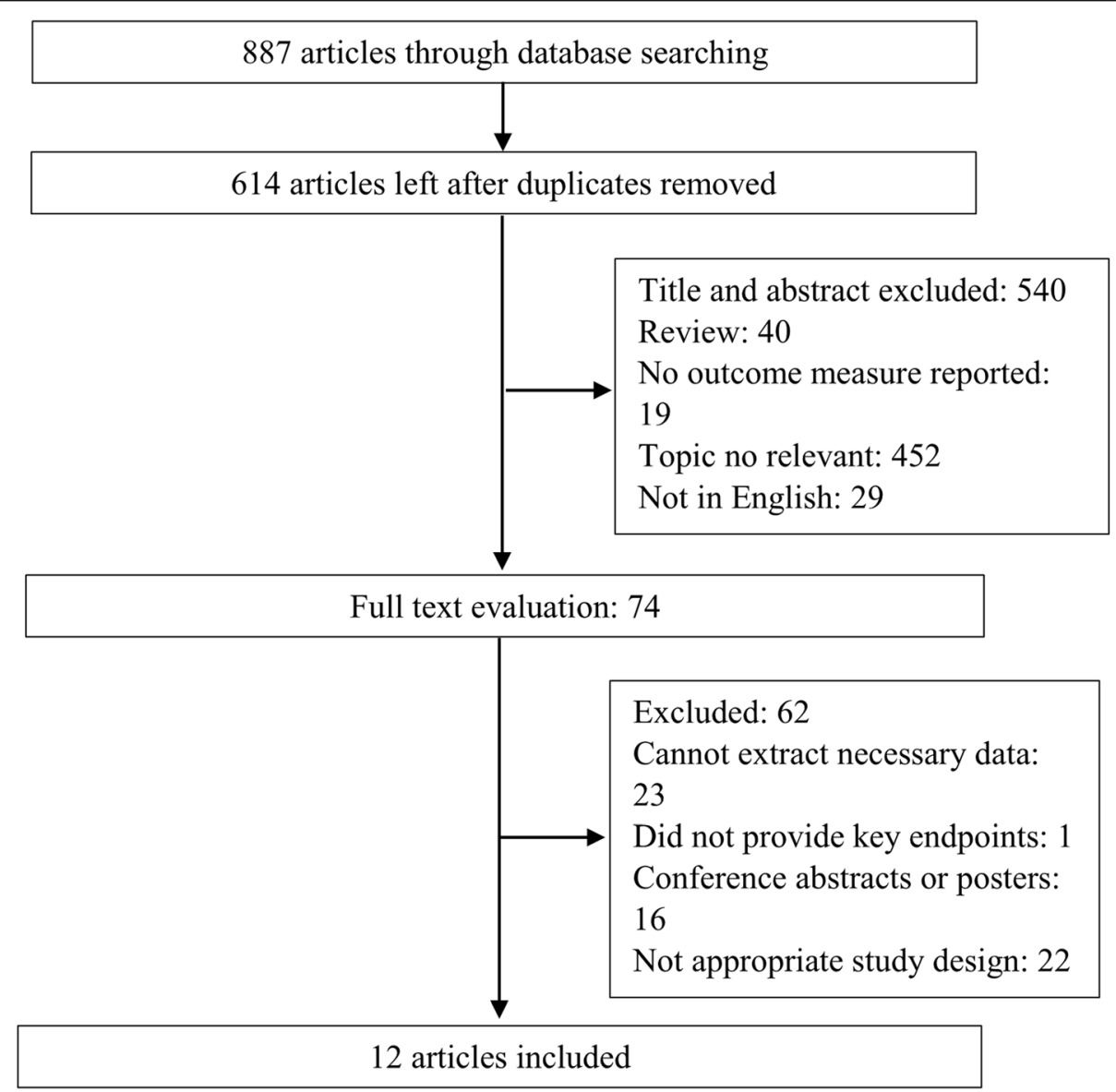

Fig. 1 Flow chart of the study selection process 
radius", "distal radial", "fracture", "fixator", and "volar locking plate" were used to search potential articles according to the Preferred Reporting Items for Systematic Reviews and Meta-Analyses (PRISMA) statement [18]. With the aim of finding more relevant studies, studies and reviews on the same or similar topics were checked. Google Scholar was also employed to search potential studies.

\section{Eligibility criteria}

The criteria to identify potential articles were: (1) RCTs that aimed to assess the outcome of VLP versus EF in unstable distal radius fractures, (2) the participants were cases clearly diagnosed with unstable distal radius fractures, (3) studies that reported functional outcome, (4) data of the characteristic outcome of participants could be extracted, (5) study was published in the English language, (6) the articles that reported more results were selected in the case when multiple populations were reported in an overlapping sample.

The studies were excluded if they were case reports, letters, brief reports, communications, reviews, non- randomized studies, non-human studies, and studies that were published in a language other than English.

Moreover, unstable distal radius fractures were defined either as [12] the fracture fragments being redisplaced following closed reduction and cast immobilization, or those fulfilling any three of the following criteria: dorsal angulation more than $20^{\circ}$, dorsal comminution, an intraarticular fracture, an associated ulnar styloid fracture, and age more than 60 years. Major complications were those leading to a reoperation, permanent nerve injury, or a persistently reduced level of function, while the minor complications were defined as either transient or those that did not affect one's final level of function.

\section{Data obtaining}

All the studies obtained initially from the electronic databases were evaluated by two investigators independently. All necessary data and information were extracted using a standardized form independently by the same two investigators. All discrepancies on the data that could not be solved by consensus were discussed and settled with another reviewer. For each included study,

Table 1 Characteristics of the included studies

\begin{tabular}{|c|c|c|c|c|c|c|c|c|}
\hline \multirow[t]{2}{*}{ Study included } & \multirow[t]{2}{*}{ Country } & \multirow{2}{*}{$\begin{array}{l}\text { Age, years } \\
\text { (range, VLP/ } \\
\text { EF) }\end{array}$} & \multirow{2}{*}{$\begin{array}{l}\text { Male } \\
\text { (\%) } \\
\text { (VLP/ } \\
\text { EF) }\end{array}$} & \multirow{2}{*}{$\begin{array}{l}\mathrm{N} \\
\text { (VLP/ } \\
\mathrm{EF)}\end{array}$} & \multirow{2}{*}{$\begin{array}{l}\text { Follow- } \\
\text { up } \\
\text { period } \\
\text { (month) }\end{array}$} & \multirow{2}{*}{$\begin{array}{l}\text { AO } \\
\text { classification } \\
(\% \text { of } A / B / C)\end{array}$} & \multicolumn{2}{|l|}{ Intervention } \\
\hline & & & & & & & VLP & EF \\
\hline Egol, et al., 2008 [25] & United States & $\begin{array}{l}52.2(19-87) / \\
49.9(18-78)\end{array}$ & $61 / 62$ & $39 / 38$ & 12 & $37 / 4 / 59$ & VLP & Bridging $\mathrm{EF} \pm \mathrm{K}$-wires \\
\hline Wei, et al., 2009 [26] & United States & $\begin{array}{l}61.0 \pm 18.0 / \\
55.0 \pm 16.0^{a}\end{array}$ & $25 / 28$ & $12 / 22$ & 12 & $45 / 0 / 55$ & $\begin{array}{l}\text { Locked radial column } \\
\text { plates and VLP }\end{array}$ & Bridging $\mathrm{EF} \pm \mathrm{K}$-wires \\
\hline Wilcke, et al., 2011 [10] & Sweden & $\begin{array}{l}55.0(20-69) / \\
56.0(21-69)\end{array}$ & $24 / 23$ & $33 / 30$ & 12 & $76 / 0 / 24$ & VLP & Bridging $\mathrm{EF} \pm \mathrm{K}$-wires \\
\hline Jeudy, et al., 2012 [11] & France & $\begin{array}{l}64.7 \pm 3.7 / \\
64.6 \pm 3.5^{a}\end{array}$ & $28 / 21$ & $36 / 39$ & $\begin{array}{l}24 \\
\text { weeks }\end{array}$ & 0/0/100 & $\begin{array}{l}\text { Volar fixed angle } \\
\text { plates }\end{array}$ & Bridging $\mathrm{EF} \pm \mathrm{K}$-wires \\
\hline Gradl, et al., 2013 [27] & Germany & $63(18-88)$ & $13^{b}$ & $52 / 50$ & 12 & $61 / 0 / 39$ & $\begin{array}{l}\text { Volar fixed angle } \\
\text { plates }\end{array}$ & $\begin{array}{l}\text { Non-bridging } \mathrm{EF} \pm \mathrm{K} \text { - } \\
\text { wires }\end{array}$ \\
\hline $\begin{array}{l}\text { Karantana, et al., } 2013 \\
\text { [29] }\end{array}$ & $\begin{array}{l}\text { United } \\
\text { Kingdom }\end{array}$ & $\begin{array}{l}48.0 \pm 15.0 / \\
51.0 \pm 16.0^{a}\end{array}$ & $39 / 22$ & $66 / 64$ & 12 & $42 / 52 / 6$ & VLP & Bridging $\mathrm{EF} \pm \mathrm{K}$-wires \\
\hline $\begin{array}{l}\text { Williksen, et al., } 2013 \\
\text { [28] }\end{array}$ & Norway & $54.0(20-84)$ & $20^{b}$ & $52 / 59$ & $\begin{array}{l}52 \\
\text { weeks }\end{array}$ & $26 / 0 / 74$ & $\begin{array}{l}\text { Volar fixed angle } \\
\text { plates }\end{array}$ & Bridging $\mathrm{EF} \pm \mathrm{K}$-wires \\
\hline Shukla, et al., 2014 [14] & India & $\begin{array}{l}39.3 \pm 13.1 / \\
39.0 \pm 13.1^{a}\end{array}$ & $42 / 47$ & $36 / 38$ & 12 & NA & VLP & Bridging EF \\
\hline Roh, et al., 2015 [15] & South Korea & $\begin{array}{l}54.4 \pm 10.9 \\
/ 55.3 \pm 11.2^{a}\end{array}$ & $70 / 64$ & $48 / 62$ & 12 & $0 / 0 / 100$ & VLP & Bridging $\mathrm{EF} \pm \mathrm{K}$-wires \\
\hline Navarro, et al., 2016 [16] & Sweden & $\begin{array}{l}63.0(51.0- \\
74.0) / \\
63.0(50.0- \\
74.0)\end{array}$ & $37 / 34$ & $69 / 65$ & 12 & $40 / 0 / 60$ & VLP & Bridging $\mathrm{EF} \pm \mathrm{K}$-wires \\
\hline Chung, et al., 2019 [30] & United States & $\begin{array}{l}67.3 \pm 6.2 / \\
69.5 \pm 8.4^{a}\end{array}$ & $\begin{array}{l}15.4 / \\
7.8\end{array}$ & $65 / 64$ & 12 & NA & VLP & Bridging EF \\
\hline $\begin{array}{l}\text { Hammer, et al., } 2019 \\
\text { [17] }\end{array}$ & Norway & $\begin{array}{l}56.0 \pm 10.5 / \\
54.0 \pm 12.4^{a}\end{array}$ & $30 / 33$ & $84 / 82$ & 12 & $0 / 0 / 100$ & VLP & Bridging $\mathrm{EF} \pm \mathrm{K}$-wires \\
\hline
\end{tabular}

Abbreviations: EF external fixation, VLP volar locking plates, NA not available

${ }^{a}$ means \pm standard deviation

boverall results 


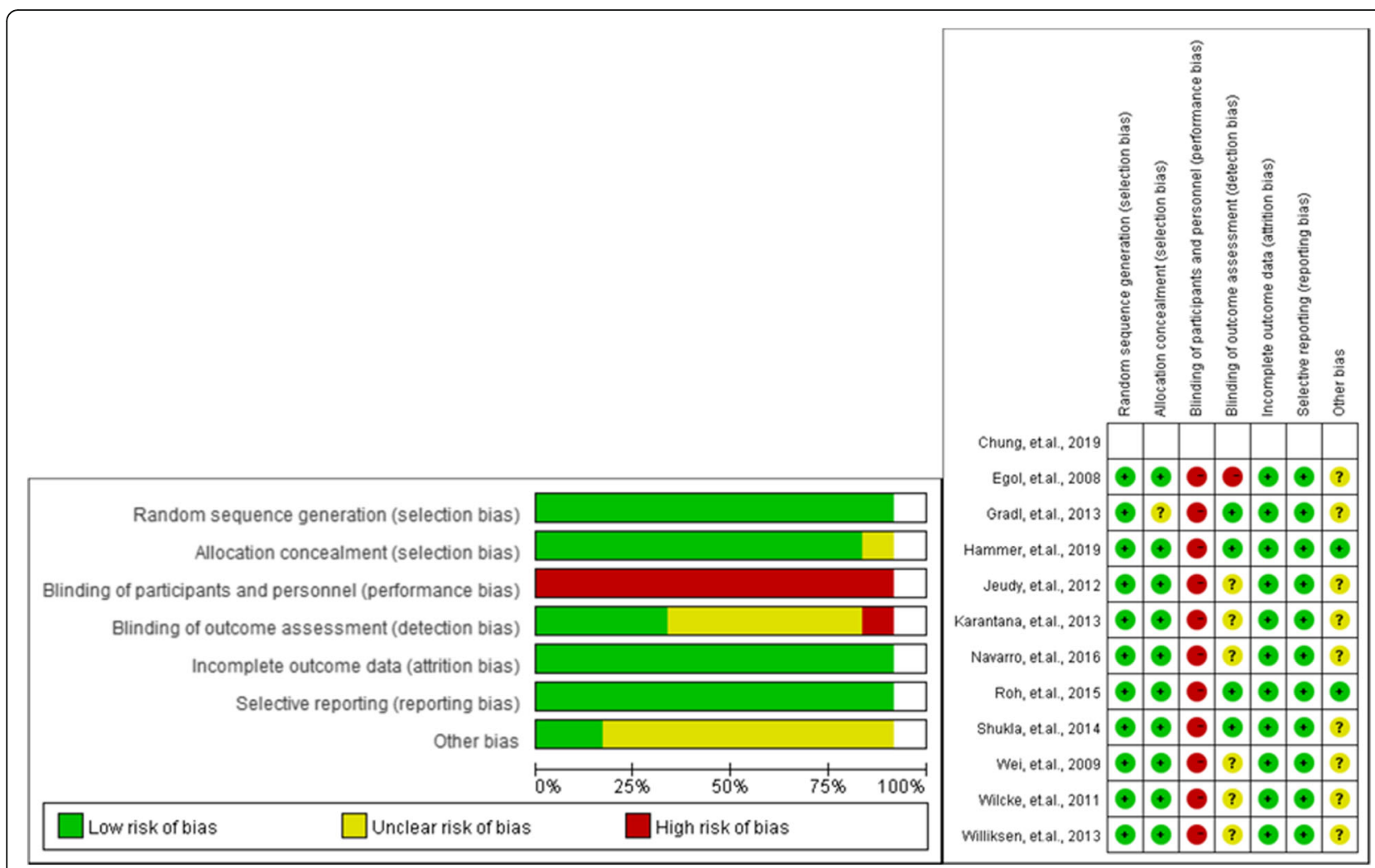

Fig. 2 Risk of bias assessment of the included studies

the following data were extracted: article characteristics (e.g., the first author, publish year, and study design), participant features (age, sex, and sample size,), therapy characteristics of VLP and EF, and outcome characteristics.

\section{Bias risk assessment}

The bias risk assessment tool, Cochrane Collaboration's Risk of Bias tool [19], was employed for each study. The bias risk of each study was graded into three categories following the guideline from lower to higher. The detailed assessment process included the following seven items: (1) sequence generation, (2) allocation concealment, (3) blinding for participants, (4) blinding for outcome assessment, (5) assessment of incomplete results, (6) completeness on presenting the data, and (7) other biases. The item for, which insufficient information was provided for them to be award a low or high risk of bias, the relevant items were judged as unclear.

\section{Assessment of the quality of studies}

The two reviewers (names of two authors) stated above independently evaluated the quality of evidence following the Jadad scale [20]. Each included study was scored from 0 to 5 according to their performance on the three items of the Jadad scale - randomized on selecting participants, blinded for grouping, and accountable for every participant. For the "randomization" and "blinding" item, one or two stars would be given for the "yes" response, and one star would be given for the answer "yes" for "accountability". For setting a minimum standard for the inclusion of a study in the current study, the study with one or two stars was deemed as having low quality [21].

\section{Statistical analysis}

Discrete variables, such as complications of each group, were estimated and pooled by risk ratio (RR) and relevant $95 \%$ confidence interval (CI). Mean difference (MD) and $95 \%$ CI were employed to pool continuous variables, such as wrist range of motion (WRM), etc. All the pooled variables were subjected to an inverse variance procedure with a random model. The $I^{2}$ statistic was used to assess the heterogeneity in each analysis. Heterogeneity in each analysis process was identified as lower $\left(I^{2}\right.$ less than $\left.25 \%\right)$, moderate $\left(I^{2}\right.$ between 25 and $50 \%)$, and higher $\left(I^{2}\right.$ more than $\left.50 \%\right)$ [22]. For the process with $50 \% \leq I^{2}$, the studies were seriatim excluded from the analysis. Begg's rank correlation [23] and Egger's weighted regression method [24] were employed to evaluate the publication biases in the analysis processes. Stratified analyses were conducted based 


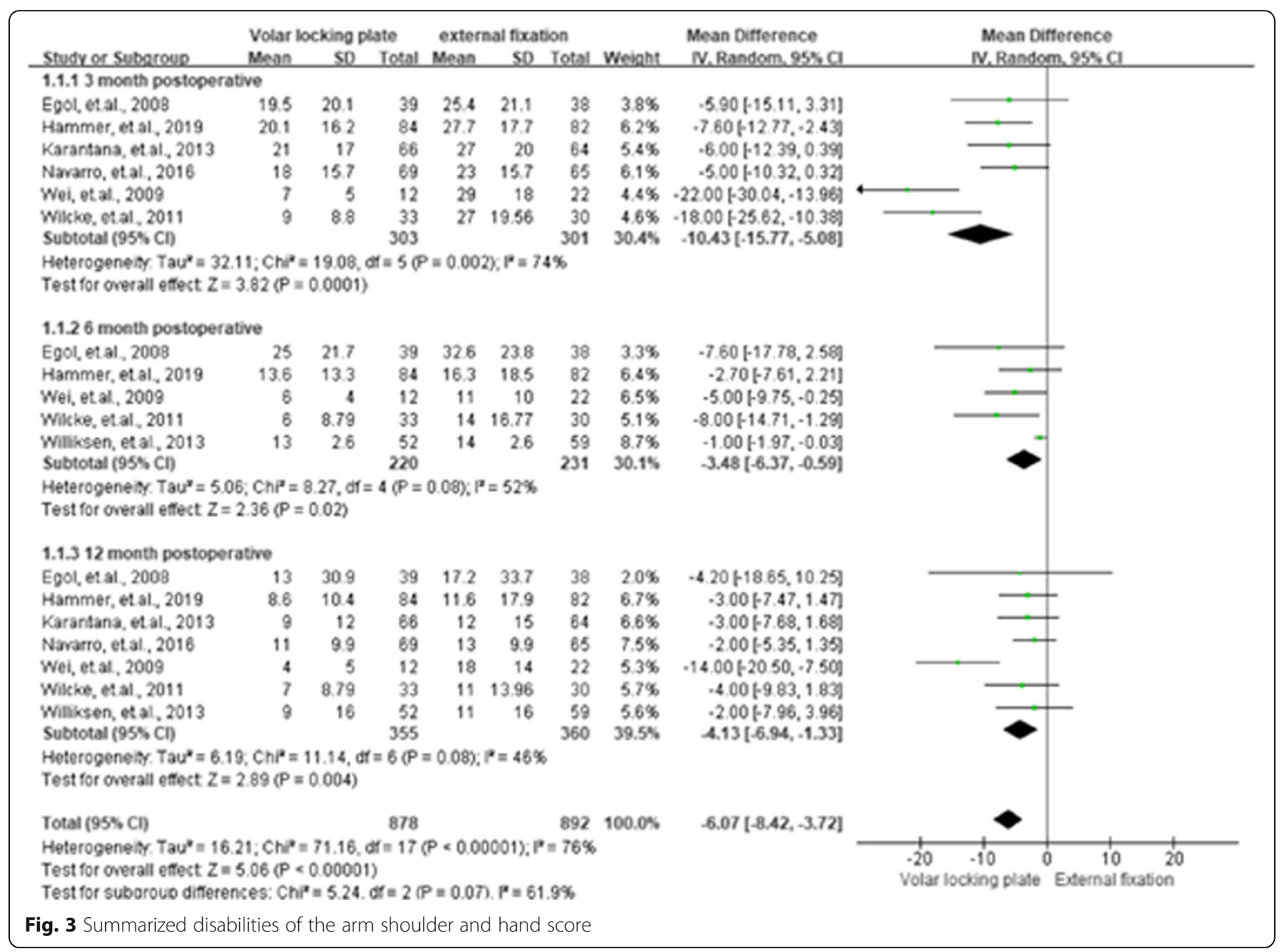

on the characteristics of the participants and the outcomes of each group. Pooled processes and forest plots were completed using Review-Manager (version 5.2, The Cochrane Collaboration, Oxford, UK). The publication bias was evaluated with STATA 15.1 (Stata Corporation, College Station, TX, USA). For all analyses, the $P$-value of less than 0.05 was deemed as statistically significant.

\section{Results}

\section{Study inclusion}

Ultimately, 887 articles were included after the initial search in the electronic datasets, among which 273 were removed due to duplication. Most of the remaining articles were removed by reading the titles or abstracts. Finally, 12 studies [10,11, 14-17, 25-30] were included in the current study by browsing 74 full-text manuscripts. The flow chart for the literature selection process can be found in Fig. 1.

\section{Study characteristics}

A total of 1205 distal radius fracture cases were included in the current study. The 12 studies were conducted in the United
States $[25,26,30]$ ( $N=$ three), Sweden $[10,16](N=$ two), Norway [17, 28] ( $N=$ two), France [17] $(N=$ one), Germany [27] ( $N=$ one), United Kingdom [29] ( $N=$ one), India [14] ( $N=$ one), and the Republic of Korea [15] $(N=$ one). The sample sizes of the 12 studies ranged between 34 and 134. The features of the participants are presented in Table 1.

\section{Risk of bias and quality assessment}

The majority of the included studies were evaluated as those with an acceptable risk of bias and quality. The majority of the studies were assessed as having a score of 3 on the Jadad scale as some of them did not conduct blinding methods. More detailed results on the risk of bias and quality assessment can be found in Fig. 2 and Supplementary Table 1, respectively.

\section{DASH scores (disabilities of the arm shoulder and hand score)}

Seven RCTs [10, 16, 17, 25, 26, 28, 29] with 715 cases reported data on DASH scores. The DASH scores for VLP were statistically lower when compared with EF at 3rd, 6th, and 12th 
month postoperation, with MDs of $-10.43(95 \% \mathrm{CI}=-15.77$ to $-5.08, P<0.01),-3.48(95 \% \mathrm{CI}=-6.37$ to $-0.59, P=0.02)$, and $-4.13(95 \% \mathrm{CI}=-6.94$ to $-1.33, P<0.01)$, respectively. The summarized results were assessed as having a slightly higher or moderate heterogeneity, with $I^{2}=74 \%, 52 \%$, and $46 \%$ for the 3rd, 6th, and 12th -month post-operation. The summarized results of the DASH scores are presented in Fig. 3.

\section{Visual analog scale scores}

As shown in Fig. 4, of the twelve RCTs, four studies [17, 25-27] provided data on VAS (visual analog scale scores) and included 379 cases. No heterogeneity $\left({ }^{2}=0 \%\right)$ for the scores of 3rd, 6th, and 12th -month post-operation was found. The VLP group had a better VAS than the EF group, with $\mathrm{MD}$ of -0.10 (95\% CI $=-0.18$ to $-0.03, P<$ $0.01)$ for the former at 6 th - month post-operation.

\section{Grip strength (GS) for the uninjured side}

As shown in Fig. 5, eight studies [10, 14, 15, 17, 25-27, 29] provided and assessed the detailed GS of the VLP and EF groups for the 3rd, 6th, and 12th -month postoperation. For the pooled MD of the two groups, all the summarized results were assessed as having higher heterogeneity $\left(I^{2}=70 \%, 81 \%\right.$, and $\left.77 \%\right)$, and the VLP group demonstrated a significantly lower GS than that of the EF group, with MD of 12.48 (95\% CI $=7.00-$
17.95, $P<0.01)$ at the 3rd month and 4.54 (95\% $\mathrm{CI}=$ $0.31-8.76, P=0.04)$ at the 6 th month for the former.

\section{WRM}

The WRM was presented in six categories of pooled flexion, extension, pronation, supination, radial deviation, and ulnar deviation. For the 3rd month, flexion $(\mathrm{MD}=5.76,95 \% \mathrm{CI}=1.46-10.07, \quad P<0.01)$, extension $(\mathrm{MD}=11.66,95 \% \mathrm{CI}=2.35-20.97, P=0.01)$, and supination $(\mathrm{MD}=10.77,95 \% \mathrm{CI}=3.29-18.25, P<0.01)$ had better performance in the VLP group than that in the EF group. Results of WRM for the 3rd, 6th, and 12th month are shown in Figs. 6, 7 and 8, respectively.

\section{Radiographic outcomes}

The outcomes on radiographic variables were evaluated at the 12th month and are presented in Fig. 9. No significant differences were observed between VLP and EF $(P>0.05)$ for the results on volar tilt, radial shortening, radial inclination, and ulnar variance.

\section{Complications}

All the 12 included RCTs reported the complication rate, and the results can be found in Fig. 10. The pooled result on complication revealed that VLP led to a lower proportion of complication compared to EF, with RR of 0.75 (95\% CI $=0.58-0.98, P=0.03$ ) for the former. For

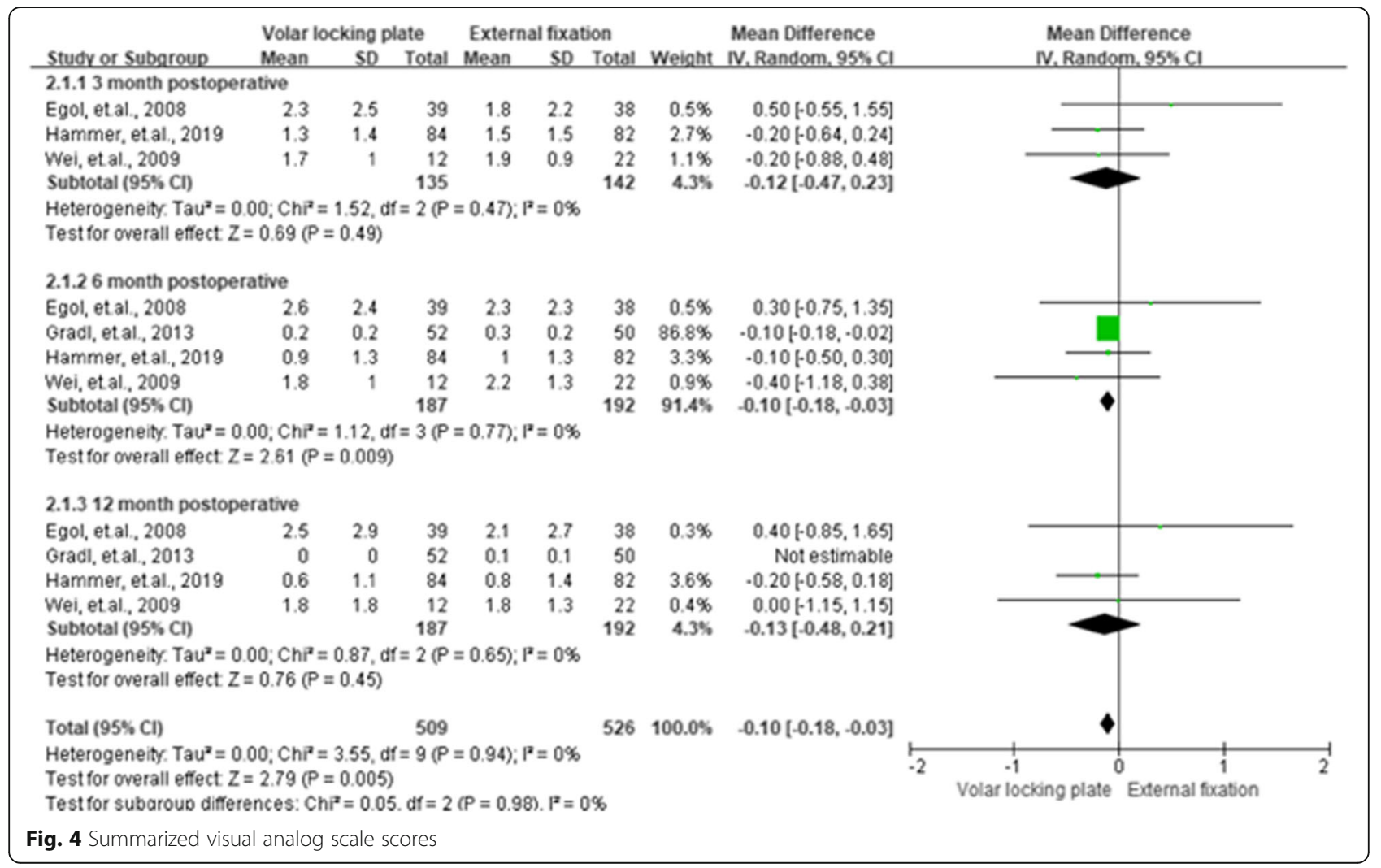




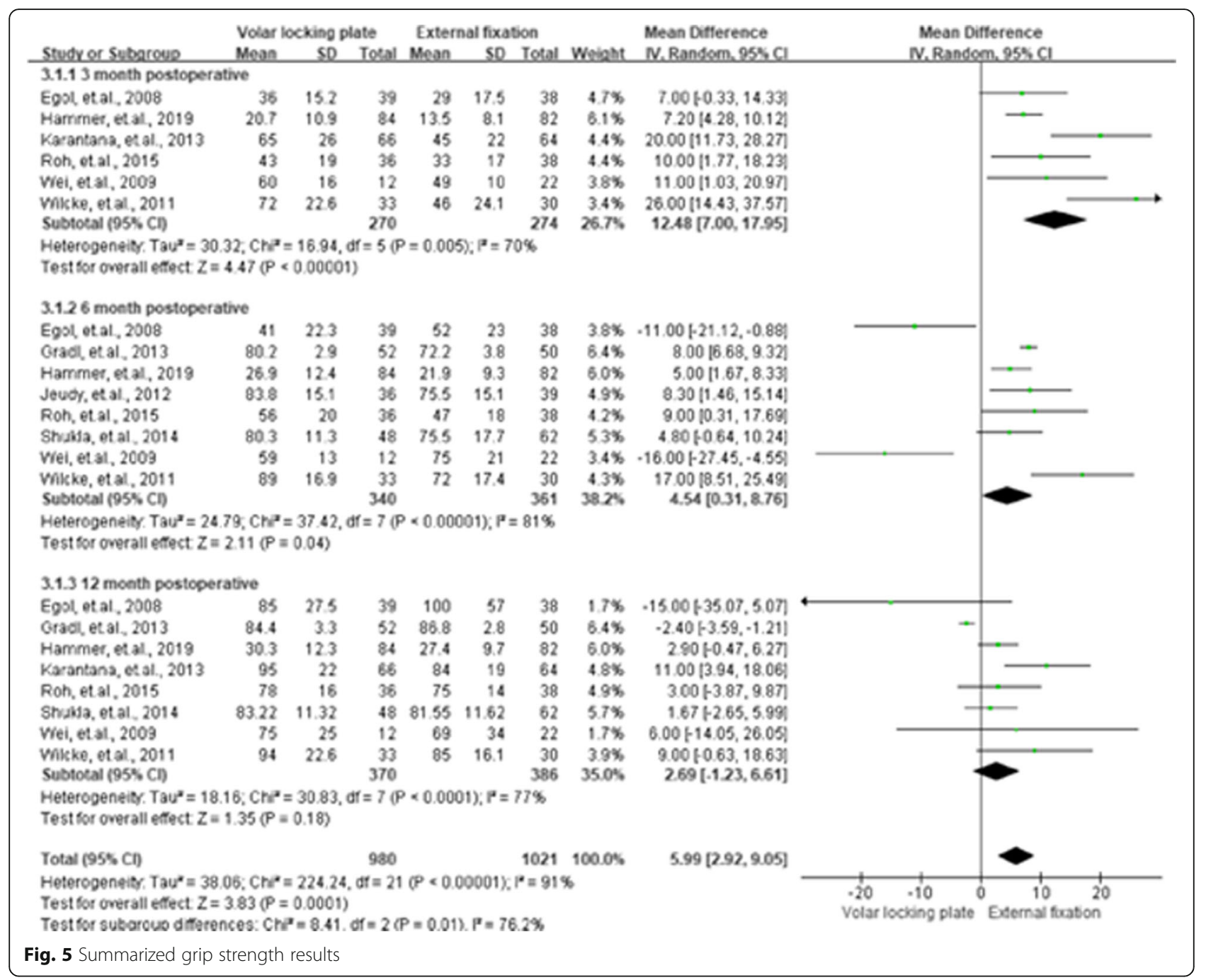

the summarized minor complication rate, the results were similar $(\mathrm{RR}=0.75,95 \% \mathrm{CI}=0.64-0.88, P<0.01)$.

\section{Heterogeneity analyses}

Sensitivity analyses were performed by excluding studies seriatim to explore the sources of heterogeneity. In the pooled analysis of DASH, GS, WRM, and radiographic outcomes, the heterogeneity exhibited became significantly lower by excluding one or two studies. The detailed results are presented in Supplementary Figs. 1, 2, 3, 4, 5 and 6.

\section{Publication bias}

No publication bias was found with Begg's rank correlation and Egger's weighted regression analysis (all $P<$ $0.05)$. The p-values for all pooled analyses are presented in Supplementary Table 2.

\section{Discussion}

In our current study on VLP versus EF for distal radius fracture cases, 12 RCTs with 1205 cases were included. Compared with EF, VLP might involve a lower DASH score and VAS score. In regard to WRM, VLP was better than EF in flexion and supination. However, EF significantly increased GS compared to VLP. No differences were observed for the radiographic parameters. For the pooled minor complication rate and total complication rate, VLP presented a slightly lower proportion of complication compared to EF.

Another study [31] addressing a similar topic observed that VLP could obtain better subjective scores and radiographic parameters. By including more RCTs with more participants, the conclusions for subjective scores would be comparable. However, the DASH scores for VLP at three, six, and twelve months exhibited a downward trend. One of the significant differences in the outcomes of VLP and EF was the DASH score in 3rd month. The result 


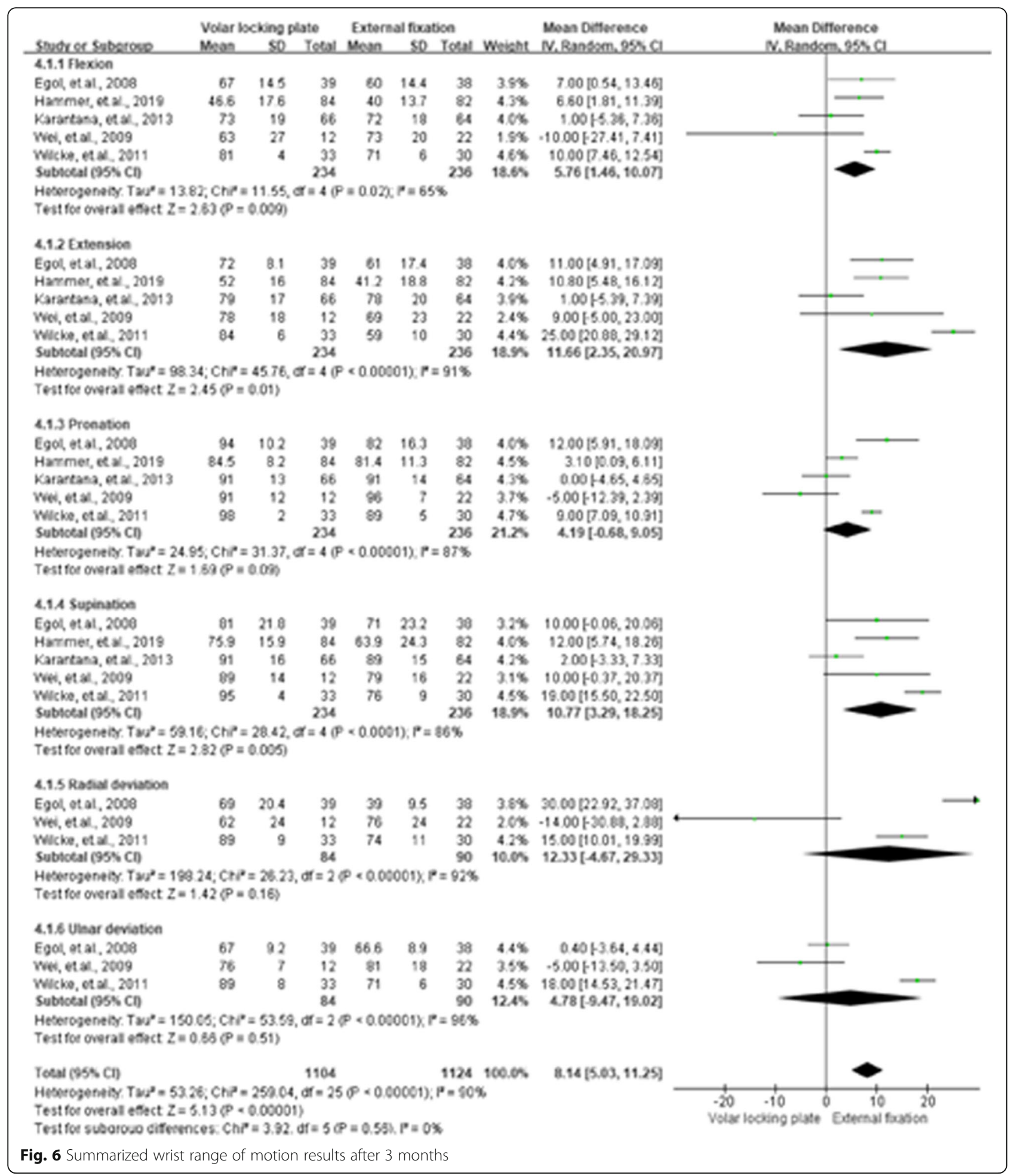

suggested that cases treated with VLP might obtain a better functional outcome at earlier stages. However, the difference in GS revealing a better outcome for EF at three or six months suggested an advantageous recovery for GS in the early rehabilitation period, while the long-term outcomes were similar. This may be attributed to the earlier rehabilitation and exercise in the group [25].

However, no differences were observed for the radiographic outcomes. With a significantly larger number of included studies conducted in various countries, the 


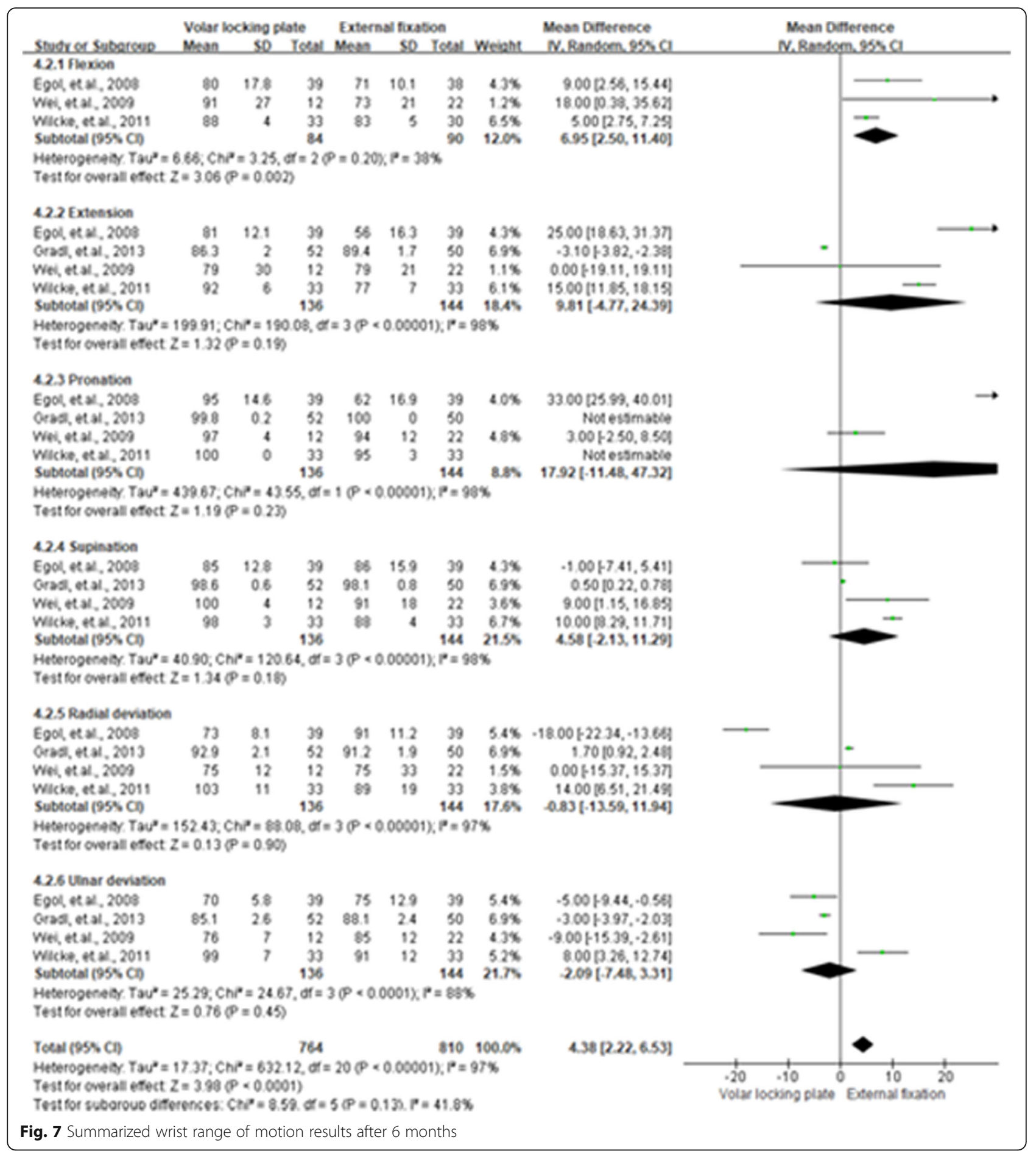

results were different from those of the meta-analysis reported by Gouk et al. [31] and Zhang et al. [32] and were similar to those of a prospective randomized trial [25].

Common complications after EF were transient superficial nerve palsy, pin track infection, and loss of fracture reduction $[25,26]$, while for VLP, they were median nerve palsy, flexor tenosynovitis, extensor tenosynovitis, and tendon rupture $[25,26]$. In our study, a significant difference was observed when assessing the overall and minor complications. In another systematic review aimed to assess the complications of distal radial fractures in the elderly population, small but clinically unimportant differences in the clinical outcomes were reported between EF and VLP [33], in addition to a higher reoperation rate after plate fixation. Moreover, VLP was reported to be associated with more 


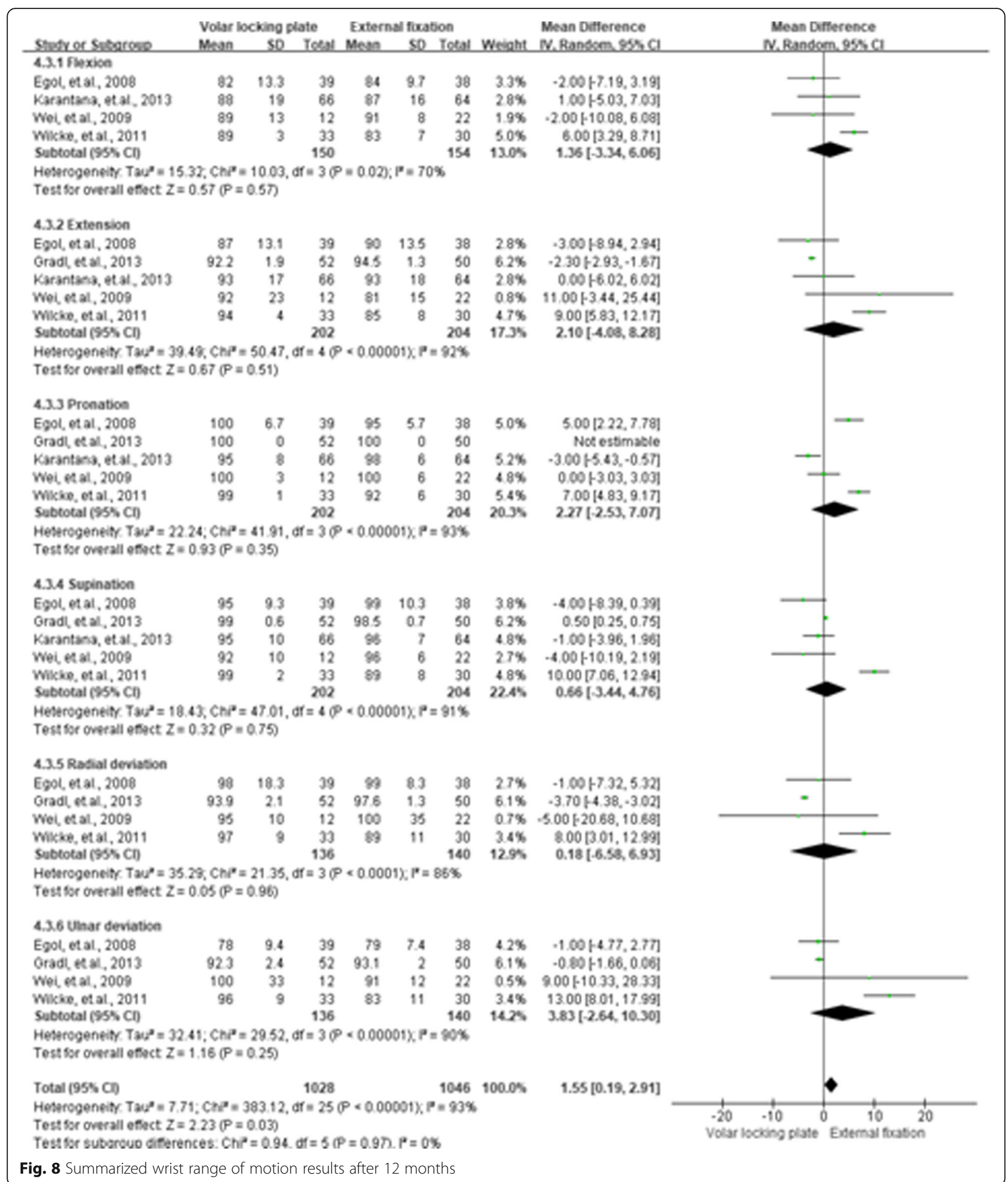

complications requiring late secondary surgery, which occurred 2 to 7 years after the fracture surgery [34, 35]. Therefore, it is important to consider the burden of complications, especially for those beyond one year after the distal radius fracture surgery. For the clinical settings, small clinical advantages might not necessarily compensate for higher costs or higher risks of complications. Although providing a stable fixation, VLP may compress and damage the flexor tendons [36]. Aiming to avoid flexor tendon problems, in clinical settings, 


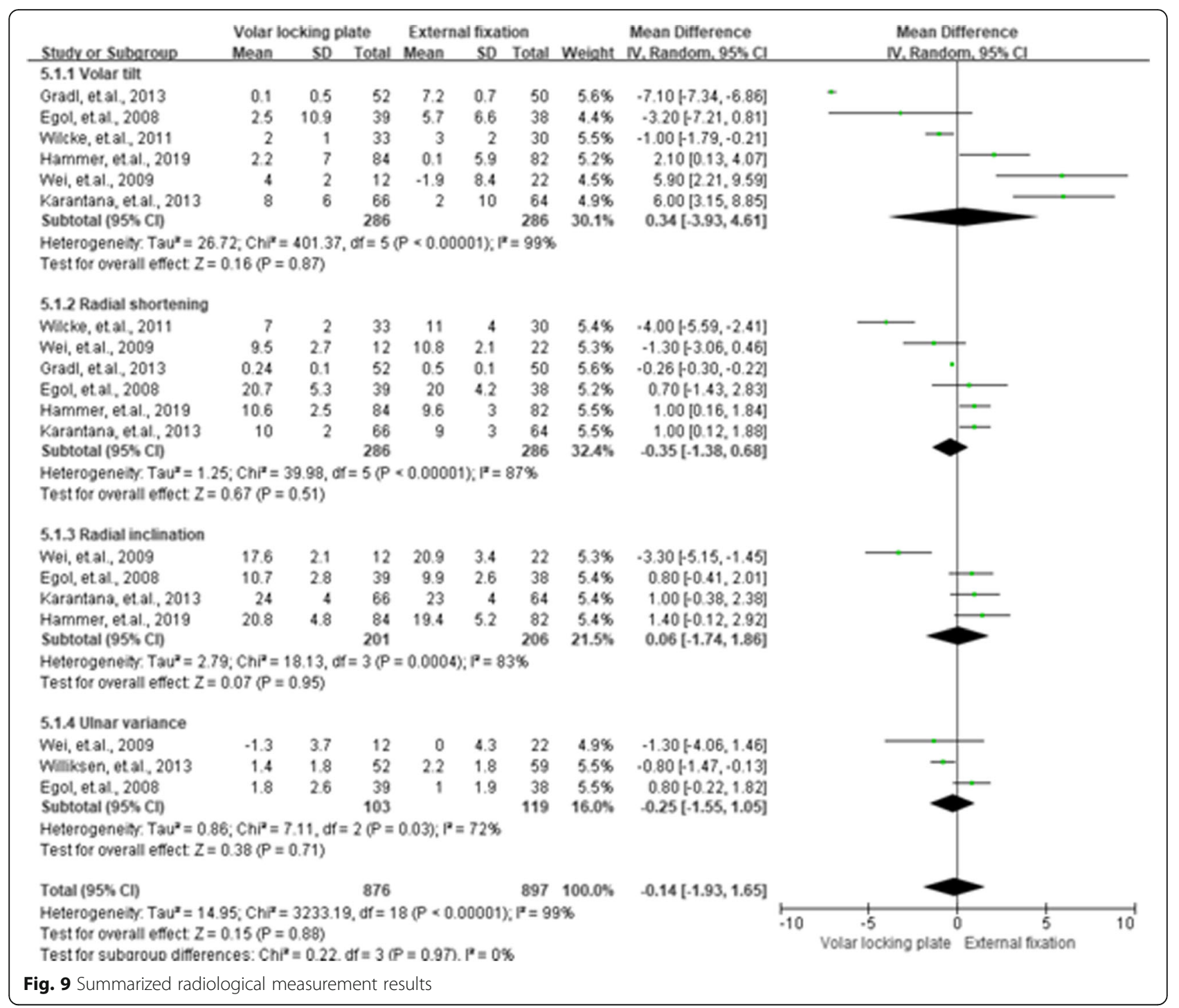

surgeons always recommend keeping the plates proximal to the volar rim. Moreover, some highly comminuted and distal fractures may not be amenable to VLP, such as fractures with multiple intra-articular fragments in the distal bone [37]. The watershed line needs to be considered for VLP. It could be an indication point for the plate placement that delimits the concave structure of the radius distal volar face [37, 38]. VLP applied distally to that point may cause tendon complications $[37,38]$. Therefore, the current meta-analysis might provide references for clinicians when dealing with distal radius fractures. Although with various AO fracture types, the results remain similar. The result was consistent with the study conducted by Hoffmann et al., who compared the $\mathrm{AO}$ type $\mathrm{B}$ and $\mathrm{C}$ fractures of the distal radius. $\mathrm{Pa}-$ tients with Type- $\mathrm{C}$ volar might experience more pain during early recovery, but ultimately their outcome was comparable with that of patients with a Type-B.
However, certain limitations of the current study should be considered when drawing conclusions. First, the majority of the included studies had limited participants and most of the studies were conducted in western countries. Therefore, we could not conduct more subgroup or sensitivity analyses. Second, when including the participants in the two groups, the majority of the researchers did not match the cases for the two groups by age or gender. The differences in age and the gender ratio in the case and control groups might cause heterogeneities and reduce reliability. Third, the process of evaluating the outcomes and the definition of the outcomes were relatively promiscuous. More than ten scores or methods were used to assess or define the outcomes. The follow-up time for assessing the outcomes in the studies ranged from 2 weeks to 5 years. Therefore, we could not have more pooled results on functional outcomes with limited studies. Fourth, none of the included studies reported comorbidities in the participants. The comorbidities might also lead to or contribute to adverse 


\begin{tabular}{|c|c|c|c|c|c|c|c|c|c|c|c|}
\hline \multirow[b]{2}{*}{ Study or Subaroup } & \multicolumn{2}{|c|}{ Volar locking plate } & \multicolumn{2}{|c|}{ External fixation } & \multirow{2}{*}{ Weight } & \multirow{2}{*}{$\begin{array}{l}\text { Risk Ratio } \\
\text { M.H. Randem, } 95 \% \mathrm{Cl}\end{array}$} & \multirow{2}{*}{\multicolumn{5}{|c|}{$\begin{array}{c}\text { Risk Ratio } \\
\text { M.H. Random.955 Cl }\end{array}$}} \\
\hline & Events & Total & Events & Total & & & & & & & \\
\hline \multicolumn{12}{|c|}{ 6.1.1 Minor complications } \\
\hline Gradl, etal., 2013 & 1 & 52 & 5 & 50 & $0.4 \%$ & $0.19[0.02,1.59\}$ & $\leftarrow$ & & & & \\
\hline Williksen, et al, 2013 & 2 & 52 & 8 & 59 & $0.8 \%$ & $0.28(0.06,1.28\}$ & $\leftarrow$ & & & - & \\
\hline Karantana, et.al., 2013 & 5 & 66 & 11 & 64 & $1.8 \%$ & $0.44(0.16,1.20)$ & & & & 一 & \\
\hline Whicke, etal., 2011 & 3 & 33 & 6 & 30 & $1.1 \%$ & $0.45(0.12,1.66)$ & & & & & \\
\hline Roh, et al., 2015 & 3 & 36 & 6 & 38 & $1.0 \%$ & $0.53(0.14,1.95)$ & & & & & \\
\hline Jeudy, et al, 2012 & 11 & 36 & 21 & 39 & $5.4 \%$ & $0.57\{0.32,1.01\rceil$ & & & & & \\
\hline Shukla, et al., 2014 & 1 & 48 & 2 & 62 & $0.3 \%$ & $0.65[0.06,6.91]$ & & & & & \\
\hline Nawarro, et al., 2016 & 11 & 69 & 13 & 65 & $3.3 \%$ & $0.80(0.38,1.65)$ & & & & & \\
\hline Chung. etal., 2019 & 17 & 65 & 20 & 64 & $5.9 \%$ & $0.84[0.48,1.45)$ & & & & & \\
\hline Egol, et al., 2008 & 8 & 39 & 7 & 38 & $2.1 \%$ & $1.11[0.45,2.77]$ & & & & & \\
\hline Wei, et.al., 2009 & 2 & 12 & 3 & 22 & $0.7 \%$ & $1.22[0.24,6.33\}$ & & & & & \\
\hline Hammer, etal., 2019 & 20 & 84 & 14 & 82 & $4.7 \%$ & $1.39[0.76,2.57]$ & & & & & \\
\hline Subtotal $(95 \% \mathrm{CJ})$ & & 592 & & 613 & $27.4 \%$ & $0.75[0.58,0.98]$ & & & & & \\
\hline Total events & 84 & & 116 & & & & & & & & \\
\hline \multicolumn{12}{|c|}{ Heterogeneity Ta $^{2}=0.01: C h \mathbf{P}^{2}=11.31, \mathrm{df}=11(\mathrm{P}=0.42): \mathrm{P}^{2}=3 \%$} \\
\hline \multicolumn{12}{|c|}{ Test for overall effect $Z=2.13(P=0.03)$} \\
\hline \multicolumn{12}{|c|}{ 6.1.2 Overall complications } \\
\hline Jeudy, et al, 2012 & 6 & 36 & 13 & 38 & $2.4 \%$ & $0.49[0.21,1.14]$ & & & & & \\
\hline Egol, et al., 2008 & 7 & 33 & 12 & 30 & $28 \%$ & $0.53[0.24,1.17]$ & & & & & \\
\hline Williksen, et al, 2013 & 13 & 36 & 22 & 39 & $6.6 \%$ & $0.64[0.38,1.07)$ & & & & & \\
\hline Naramo, etal., 2016 & 16 & 66 & 24 & 64 & $6.2 \%$ & $0.65[0.38,1.10)$ & & & & & \\
\hline Roh, etal, 2015 & 31 & 65 & 45 & 64 & $19.5 \%$ & $0.68\{0.50,0.92 \uparrow$ & & & $\longrightarrow$ & & \\
\hline Wilcke, etal., 2011 & 37 & 84 & 45 & 82 & $18.2 \%$ & $0.80(0.59,1.10)$ & & & $\because$ & & \\
\hline Gradl, et.al., 2013 & 2 & 12 & 4 & 22 & $0.7 \%$ & $0.92(0.20,4.30)$ & & & & & \\
\hline Chung, etal., 2019 & 15 & 52 & 18 & 59 & $5.3 \%$ & $0.95[0.53,1.68]$ & & & & & \\
\hline Karantana, etal., 2013 & 17 & 69 & 16 & 65 & $5.0 \%$ & $1.00\{0.55,1.81]$ & & & & & \\
\hline Wei, etal., 2009 & 11 & 52 & 10 & 50 & $3.0 \%$ & $1.06[0.49,2.27]$ & & & & & \\
\hline Shukla, et al, 2014 & 8 & 39 & 7 & 38 & $2.1 \%$ & $1.11[0.45,2.77]$ & & & & & \\
\hline Hammer, etal., 2019 & 2 & 48 & 2 & 62 & $0.5 \%$ & $1.29[0.19,8.84]$ & & & & & \\
\hline Subtotal $(95 \% \mathrm{CI})$ & & 592 & & 613 & $72.6 \%$ & $0.75[0.64,0.88]$ & & & & & \\
\hline \multirow{3}{*}{\multicolumn{12}{|c|}{$\begin{array}{l}\text { Heterogeneity. Tau }=0.00 ; C h P^{2}=6.44, d f=11(P=0.84) ; P=0 \% \\
\text { Test for overall effect } Z=3.58(P=0.0003)\end{array}$}} \\
\hline & & & & & & & & & & & \\
\hline & & & & & & & & & & & \\
\hline Total $(95 \% \mathrm{Cl})$ & & 1184 & & 1226 & $100.0 \%$ & $0.75[0.66,0.86]$ & & & $\boldsymbol{b}$ & & \\
\hline Total erents & 249 & & 334 & & & & & & & & \\
\hline \multirow{2}{*}{\multicolumn{7}{|c|}{$\begin{array}{l}\text { Heterogeneity. Tau }=0.00 ; C h P^{2}=17.67, d f=23(P=0.78) ; P=0 \% \\
\text { Test for overall effect } Z=4.18(P<0.0001)\end{array}$}} & 01 & & & & \\
\hline & & & & & & & 0.1 & & $0.5 \quad 1$ & 25 & 10 \\
\hline Test for subarous differ & ces: $\mathrm{Chi}^{\mathrm{r}}=$ & $0.0 f=1$ & $(P=0.99)$. & $=0 \%$ & & & & & locking plate E & External foxation & \\
\hline ig. 10 Summarized co & plications & & & & & & & & & & \\
\hline
\end{tabular}

outcomes. Therefore, the various potential comorbidities might also cause heterogeneities and even reduce the reliability of the results.

\section{Conclusions}

The current study assessed VLP versus EF in terms of the outcomes for distal radius fractures. VLP was observed to have a better DASH score, VAS score, and part of WRM, but a lower GS. Regarding the radiographic outcomes, VLP and EF demonstrated similar results. However, cases might have a lower complication rate when treating with VLP. VLP might benefit the cases more than EF and could be a preferential surgical technique for distal radius fracture patients. In the future, RCTs with a larger sample size and RCTs with matched characteristics of the cases and severity degrees of the patients are needed to detect more potentially important differences.

\section{Abbreviations}

VLP: Volar locking plate; EF: External fixation; RCT: Randomized controlled trials; RR: Risk ratio; Cl: Confidence interval; MD: Mean difference; WRM: Wrist range of motion; GS: Grip strength

\section{Supplementary Information}

The online version contains supplementary material available at https://doi. org/10.1186/s12891-021-04312-7.

\section{Additional file 1.}

Additional file 2: Supplementary Figure1. Heterogeneityanalysis for summarized disabilities of the arm shoulder and hand

score. Supplementary Figure2. Heterogeneityanalysis for summarized grip strength. Supplementary Figure3. Heterogeneityanalysis for summarized wrist range of motion after 3 months. Supplementary Figure4. Heterogeneityanalysis for summarized wrist range of motion after 6 months. Supplementary Figure5. Heterogeneityanalysis for summarized wrist range of motion after 12 months. Supplementary Figure6. Heterogeneityanalysis for summarized radiological

measurement. Supplementary Table 1. Quality assessment ofincluded studies by Jadad score. Supplementary Table 2. Publication bias

ofsummarized outcomes. 


\section{Acknowledgements}

None.

\section{Authors' contributions}

QG and XX contributed to the study design and writing of the manuscript. DC performed the data collection and data analysis. YH and XL edited the manuscript. All authors read and approved the final version of the manuscript.

\section{Funding}

None.

\section{Availability of data and materials}

All data generated or analyzed during this study are included in this article [and its supplementary information files].

\section{Declarations}

Ethics approval and consent to participate

Not applicable.

\section{Consent for publication}

Not applicable.

\section{Competing interests}

The authors declare that they have no competing interests.

\section{Author details}

'Department of Orthopedics, The First People's Hospital of Longquanyi District, 610100 Chengdu, China. ${ }^{2}$ Department of Anesthesiology, The First People's Hospital of Longquanyi District, 610100 Chengdu, China.

\section{Received: 5 December 2020 Accepted: 30 April 2021}

\section{Published online: 12 May 2021}

\section{References}

1. Singer BR, McLauchlan GJ, Robinson CM, Christie J: Epidemiology of fractures in 15,000 adults: the influence of age and gender. J Bone Joint Surg Br 1998, 80(2):243-248.

2. Paksima N, Panchal A, Posner MA, Green SM, Mehiman CT, Hiebert R: A meta-analysis of the literature on distal radius fractures: review of 615 articles. Bull Hosp Jt Dis 2004, 62(1-2):40-46.

3. Kawaguchi S, Sawada K, Nabeta Y, Hayakawa M, Aoki M: Recurrent dorsal angulation of the distal radius fracture during dynamic external fixation. J Hand Surg Am 1998, 23(5):920-925

4. Wolf JC, Weil WM, Hanel DP, Trumble TE: A biomechanic comparison of an internal radiocarpal-spanning 2.4-mm locking plate and external fixation in a model of distal radius fractures. J Hand Surg Am 2006, 31(10):1578-1586.

5. Orbay JL, Fernandez DL: Volar fixation for dorsally displaced fractures of the distal radius: a preliminary report. J Hand Surg Am 2002, 27(2):205-215.

6. Downing ND, Karantana A: A revolution in the management of fractures of the distal radius? J Bone Joint Surg Br 2008, 90(10):1271-1275.

7. Abramo A, Kopylov P, Geijer M, Tägil M: Open reduction and internal fixation compared to closed reduction and external fixation in distal radial fractures: a randomized study of 50 patients. Acta Orthop 2009, 80(4):478-485.

8. Kandemir U, Matityahu A, Desai R, Puttlitz C: Does a volar locking plate provide equivalent stability as a dorsal nonlocking plate in a dorsally comminuted distal radius fracture?: a biomechanical study. J Orthop Trauma 2008, 22(9):605-610

9. Cooper EO, Segalman KA, Parks BG, Sharma KM, Nguyen A: Biomechanical stability of a volar locking-screw plate versus fragment-specific fixation in a distal radius fracture model. Am J Orthop (Belle Mead NJ) 2007, 36(4):E46-49.

10. Wilcke MK, Abbaszadegan $\mathrm{H}$, Adolphson PY: Wrist function recovers more rapidly after volar locked plating than after external fixation but the outcomes are similar after 1 year. Acta Orthop 2011, 82(1):76-81.

11. Jeudy J, Steiger $V$, Boyer $P$, Cronier $P$, Bizot $P$, Massin $P$ : Treatment of complex fractures of the distal radius: a prospective randomised comparison of external fixation 'versus' locked volar plating. Injury 2012, 43(2):174-179

12. Walenkamp MM, Bentohami A, Beerekamp MS, Peters RW, van der Heiden R, Goslings JC, Schep NW: Functional outcome in patients with unstable distal radius fractures, volar locking plate versus external fixation: a metaanalysis. Strategies in trauma and limb reconstruction 2013, 8(2):67-75.

13. Li-hai Z, Ya-nan W, Zhi M, Li-cheng Z, Hong-da L, Huan Y, Xiao-xie L, Pei-fu $\mathrm{T}$ : Volar locking plate versus external fixation for the treatment of unstable distal radial fractures: a meta-analysis of randomized controlled trials. J Surg Res 2015, 193(1):324-333.

14. Shukla R, Jain RK, Sharma NK, Kumar R: External fixation versus volar locking plate for displaced intra-articular distal radius fractures: a prospective randomized comparative study of the functional outcomes. J Orthop Traumatol 2014, 15(4):265-270.

15. Roh YH, Lee BK, Baek JR, Noh JH, Gong HS, Baek GH: A randomized comparison of volar plate and external fixation for intra-articular distal radius fractures. J Hand Surg Am 2015, 40(1):34-41.

16. Mellstrand Navarro C, Ahrengart L, Törnqvist H, Ponzer S: Volar Locking Plate or External Fixation With Optional Addition of K-Wires for Dorsally Displaced Distal Radius Fractures: A Randomized Controlled Study. J Orthop Trauma 2016, 30(4):217-224.

17. Hammer OL, Clementsen S, Hast J, Šaltytè Benth J, Madsen JE, Randsborg $\mathrm{PH}$ : Volar Locking Plates Versus Augmented External Fixation of IntraArticular Distal Radial Fractures: Functional Results from a Randomized Controlled Trial. J Bone Joint Surg Am 2019, 101(4):311-321.

18. Liberati A, Altman DG, Tetzlaff J, Mulrow C, Gøtzsche PC, loannidis JP, Clarke M, Devereaux PJ, Kleijnen J, Moher D: The PRISMA statement for reporting systematic reviews and meta-analyses of studies that evaluate healthcare interventions: explanation and elaboration. BMJ 2009, 339:b2700.

19. Higgins JP, Altman DG, Gotzsche PC, Juni P, Moher D, Oxman AD, Savovic J, Schulz KF, Weeks L, Sterne JA et al.: The Cochrane Collaboration's tool for assessing risk of bias in randomised trials. BMJ 2011, 343:d5928.

20. Jadad AR, Moore RA, Carroll D, Jenkinson C, Reynolds DJ, Gavaghan DJ, McQuay HJ: Assessing the quality of reports of randomized clinical trials: is blinding necessary? Control Clin Trials 1996, 17(1):1-12

21. SD S: Statistical Evidence in Medical Trials: What Do the Data Really Tell Us. Oxford University Press 2006

22. Higgins JP, Thompson SG, Deeks JJ, Altman DG: Measuring inconsistency in meta-analyses. BMJ 2003, 327(7414):557-560.

23. Begg CB, Mazumdar M: Operating characteristics of a rank correlation test for publication bias. Biometrics 1994, 50(4):1088-1101.

24. Seagroatt $\mathrm{V}_{\text {... }}$ Stratton I,. Bias in meta-analysis detected by a simple, graphical test. Test had $10 \%$ false positive rate. Bmj British Medical Journal 1997, 316(7129):469-471.

25. Egol K, Walsh M, Tejwani N, McLaurin T, Wynn C, Paksima N: Bridging external fixation and supplementary Kirschner-wire fixation versus volar locked plating for unstable fractures of the distal radius: a randomised, prospective trial. J Bone Joint Surg Br 2008, 90(9):1214-1221.

26. Wei DH, Raizman NM, Bottino CJ, Jobin CM, Strauch RJ, Rosenwasser MP: Unstable distal radial fractures treated with external fixation, a radial column plate, or a volar plate. A prospective randomized trial. J Bone Joint Surg Am 2009, 91(7):1568-1577

27. Gradl G, Gradl G, Wendt M, Mittlmeier T, Kundt G, Jupiter JB: Non-bridging external fixation employing multiplanar K-wires versus volar locked plating for dorsally displaced fractures of the distal radius. Arch Orthop Trauma Surg 2013, 133(5):595-602.

28. Williksen JH, Frihagen F, Hellund JC, Kvernmo HD, Husby T: Volar locking plates versus external fixation and adjuvant pin fixation in unstable distal radius fractures: a randomized, controlled study. J Hand Surg Am 2013, 38(8):1469-1476.

29. Karantana A, Downing ND, Forward DP, Hatton M, Taylor AM, Scammell BE, Moran CG, Davis TR: Surgical treatment of distal radial fractures with a volar locking plate versus conventional percutaneous methods: a randomized controlled trial. J Bone Joint Surg Am 2013, 95(19):1737-1744.

30. Chung KC, Malay S, Shauver MJ, Kim HM: Assessment of Distal Radius Fracture Complications Among Adults 60 Years or Older: A Secondary Analysis of the WRIST Randomized Clinical Trial. JAMA network open 2019, 2(1):e187053.

31. Gouk CJC, Bindra RR, Tarrant DJ, Thomas MJE: Volar locking plate fixation versus external fixation of distal radius fractures: a meta-analysis. J Hand Surg Eur Vol 2018, 43(9):954-960

32. Fu Q, Zhu L, Yang $P$, Chen A: Volar Locking Plate versus External Fixation for Distal Radius Fractures: A Meta-analysis of Randomized Controlled Trials. Indian J Orthop 2018, 52(6):602-610.

33. Diaz-Garcia RJ, Oda T, Shauver MJ, Chung KC: A systematic review of outcomes and complications of treating unstable distal radius fractures in the elderly. J Hand Surg Am 2011, 36(5):824-835 e822. 
34. Landgren M, Jerrhag D, Tagil M, Kopylov P, Geijer M, Abramo A: External or internal fixation in the treatment of non-reducible distal radial fractures? Acta Orthop 2011, 82(5):610-613.

35. Williksen JH, Husby T, Hellund JC, Kvernmo HD, Rosales C, Frihagen F: External Fixation and Adjuvant Pins Versus Volar Locking Plate Fixation in Unstable Distal Radius Fractures: A Randomized, Controlled Study With a 5Year Follow-Up. J Hand Surg Am 2015, 40(7):1333-1340.

36. Kara A, Celik H, Oc Y, Uzun M, Erdil M, Tetik C: Flexor tendon complications in comminuted distal radius fractures treated with anatomic volar rim locking plates. Acta Orthop Traumatol Turc 2016, 50(6):665-669.

37. Brogan DM, Richard MJ, Ruch D, Kakar S: Management of Severely Comminuted Distal Radius Fractures. J Hand Surg Am 2015, 40(9):19051914.

38. Duprat A, Diaz J, Vernet P, Gouzou S, Facca S, Igeta Y, Liverneaux P: Volar Locking Plate Fixation of Distal Radius Fractures: Splint versus Immediate Mobilization. J Wrist Surg 2018, 7(3):237-242.

\section{Publisher's Note}

Springer Nature remains neutral with regard to jurisdictional claims in published maps and institutional affiliations.

Ready to submit your research? Choose BMC and benefit from:

- fast, convenient online submission

- thorough peer review by experienced researchers in your field

- rapid publication on acceptance

- support for research data, including large and complex data types

- gold Open Access which fosters wider collaboration and increased citations

- maximum visibility for your research: over $100 \mathrm{M}$ website views per year

At $\mathrm{BMC}$, research is always in progress.

Learn more biomedcentral.com/submissions 